\title{
THE ORANG-UTAN IN NORTH BORNEO
}

\section{By Ken Stott, Jr., Research Associate; C. Jackson Selsor, Primate Studies Programme}

\section{San Diego Natural History Museum, San Diego, California}

In October, 1959, Karl W. Kenyon, Research Biologist of the U.S. Fish and Wildlife Service, and the writers, spent three weeks in North Borneo observing wild primates. During this brief period, we questioned both European and native residents of the Colony on the relative abundance of orang-utans (Pongo pygmaeus) in various sectors, and we carefully recorded such indications as we ourselves noted. Although our own encounters with wild orang-utans were limited, we saw numerous nests, many of recent construction. The results of our inquiries and observations were encouraging enough for us to conclude that the orang in North Borneo is, for the present, in no danger of extinction and that it survives in moderate numbers wherever suitable habitat exists. This in itself should offer sufficient inducement to afford every possible sort of protection to the North Bornean survivors of a species that, elsewhere within its comparatively limited range, is becoming scarce or has already disappeared altogether.

During our stay in North Borneo, both government officials and representatives of private lumbering interests were exceedingly helpful in their advice and suggestions, and materially generous with their aid in furthering our project. We wish especially to thank P. F. Burgess of the Office of the Conservator of Forests, D. I. Nicholson, ecologist of that department, and also R. M. MacPherson and E. Booker both of the British Borneo Timber Company.

The observation of wild orang-utans is not an easy matter, both because of the silent and sedentary nature of the creature itself and because of the nature of its habitat. Although other species of ape inhabit similarly dense and tangled rain forests, their quick movements and voices often serve to disclose their whereabouts. In the past we have found vocalizations aid enormously in revealing the location of chimpanzees, siamangs, and various species of gibbons. Even with the relatively restrained gorillas, an occasional grunt, bark, or even a roar or an outburst of exuberant chest-beating, attracts immediate attention. All these gregarious apes move, as a rule, hastily through the forest when alarmed, and these actions frequently prove detrimentally revealing. 
With orang-utans, however, vocalization is quite limited, and their progress through the forest is seldom audible. The foraging of gorillas is often accompanied by the sounds of the breaking of bamboos. A crashing of branches not infrequently draws attention to the arboreal meanderings of gibbon or chimpanzee troops. But adult orangs, being less gregarious than other apes, tend to limit their conversation to periods of challenge and other forms of emergency. Their characteristically slow and deliberate movements make them difficult to see in the shadowy depths of the forest, and of course the density of the vegetation is strongly in their favour. Even what sometimes seems to be an innate curiosity helps them to escape detection, in that it causes them to stay more or less motionless, rather than attract attention by moving away. Often when human beings come into view, orangs sit quietly above, watching the unsuspecting intruders pass beneath. Even when detected, orangs may continue to observe the intruders with what appears to be an entirely mutual interest. In similar circumstances, the average chimpanzee, gorilla, or gibbon would scramble for cover, perhaps even calling during its retreat. But in our experience only orangs and siamangs, after detection in an exposed location will customarily remain either watching their human observers or indifferent to to them. On one occasion, a fully adult female orang-utan, quite aware of our presence, sat for more than five minutes in bright midday sunlight watching us, apparently feeling as much curiosity about us as we felt about her.

The comparatively subdued behaviour of these shaggy, red apes results in a surprising lack of awareness among human neighbours of their presence. In the Lungmanis area, for example we were repeatedly informed that only during August, the season of the durian fruit, were orangs to be found. Yet along one side of a mile section of railroad track, we observed more than fifty orang-utan nests as well as orang-utans themselves, and this not in the durian season! Along this one mile of track, scores of native workers, Malayan and Chinese and their European superintendents pass daily, either on foot or by lumber trains. Yet during two weeks in the area, we received not one report of orang-utans being seen. Our remarks are not a reflection on the power of observation of the local residents, but suggest how easily and perhaps consistently orang-utans escape notice.

Apparently when the durians are ripe, orang-utans venture into somewhat more open situations, drawn by the lure of one of their favourite foods. Upon such occasions, they reveal themselves to even the least discerning of their human neighbours. 
We were told of one female orang-utan with an infant, which established temporary residence in a durian tree growing on the edge of a clearing in plain view of a European residence and remained there for six days. During this period, hordes of people visited the clearing to view the orangs which appeared quite unconcerned by their sudden popularity. When the yield of the durian tree became exhausted, mother and infant unceremoniously departed in search of some other jungle grocery.

Generally, orang-utans seem little affected by the proximity of human beings or by the ceaseless commotion of human activities in nearby villages. The greatest orang population at Lungmanis was that between one and two miles along the railroad line. People were constantly in view during the day, trolleys and lumber-laden trains roared by at regular intervals, and the noises from an adjacent village were always to be heard.

Wherever we went in lowland primary forest areas in North Borneo, we found the tell-tale nests which indicated irrefutably the presence of orangs. But the type of vegetation inhabited by the greatest number of orang-utans seemed to be that from which large trees of commercial value had been removed several years before. In these logged-over areas, big trees without commercial value had been left standing and had again grown the large crowns damaged during lumber operations. Around these surviving large trees a dense tangle of second growth forest had arisen. Here the tops of second growth trees supported many more orang nests than we were able to count in any equal sector of primary forest.

P. F. Burgess expressed the belief that orang-utans quickly re-occupy areas that have been logged over, and indeed appear to prefer them to primary forest. Unless persecuted they pay little attention to human proximity. Our own limited observations would tend to confirm his statements.

Any attempt at an approximation of the number of orangutans in North Borneo would be meaningless : an actual count would be impossible, and no accurate study has been made as to the number which any given area of either primary or second growth forest can support. The extent of lowland primary forest in North Borneo is incredibly vast and the inroads which lumbering activities have so far made are negligible. This, coupled with the fact that orang-utans will re-occupy and subsequently thrive in logged-over forests would suggest that the species is in no immediate danger in North Borneo. Mr. Burgess believes that orang-utans are to be found wherever proper 
habitat exists in the Colony, and we found his convictions shared by all other authorities with whom we spoke.

Orang-utans are afforded full legal protection in North Borneo. Poaching is minimal, but we were told of two fairly recent incidents in which Dyaks had killed adult female orangs to obtain the young alive. In both cases, the infants were confiscated by the government and sent to zoos in Europe. One official estimated that perhaps six or seven orangs were killed in such a manner each year. On the whole, North Bornean natives do not seem greatly inclined to trap or kill primates of any sort for food, since they prefer other types of meat. Consequently gibbons, leaf monkeys and macaques are plentiful in uncultivated areas.

This does not mean that we have no qualms about the future of the orang or any other primate in North Borneo. The tragic history of so many forms of wild life in neighbouring Sarawak, where the orang has practically vanished, and in Brunei, could easily be repeated here. We feel strongly that a national wild life reserve should be established in the Sandakan area especially to protect populations of orang-utans, gibbons, proboscis monkeys, and other primates in this highly favoured region. This we have recommended to an entirely receptive Office of the Conservator of Forests. 